\title{
Staff perceptions of families in rural residential aged care
}

\author{
Kaye Elizabeth Ervin ${ }^{1,2}$, Maddalena Cross $^{1}$, Alison Koschel ${ }^{1}$ \\ 1. Rural Health Academic Centre, University of Melbourne, Australia. 2. Cobram District Health, Australia \\ Correspondence: Kaye Elizabeth Ervin. Address: Research Fellow, Rural Health Academic Network, University of \\ Melbourne, Cobram, Victoria, Austrialia. E-mail: ervink@humehealth.org.au
}

Received: August 28, 2012

Accepted: November 21, 2012

Online Published: December 3, 2012

DOI : $10.5430 /$ jha.v2n1p59

URL: http://dx.doi.org/10.5430/jha.v2n1p59

\section{Abstract}

Objective: The aim of the project was to identify staff opinions of families in rural residential aged care, in light of the negative perceptions reported in the literature, to determine any similar opinions which may be barriers to introducing increased person-centred care practices.

Method: A convenience sample of staff from three rural aged care facilities voluntarily participated in a quantative survey by completing and returning a questionnaire on their opinion about working with families in aged care settings.

Results: Forty six staff responded (46.9\% return rate); with $85 \%$ of staff reporting that families should be encouraged to participate in the care of their relatives. However, the findings also report $87 \%$ of staff perceived that family members were hostile without good reason and 76\% report families were angry with aged care workers and undermined their treatment efforts.

Conclusions: Although numerous studies exploring staff/family relationships in Australian and overseas settings are reported in the literature, this is the first rural focused study of its kind. Family participation in all aged care settings is essential for provision of person-centred care practices. Current negative perceptions of families expressed by rural aged care staff requires further research to explore possible solutions to improving staff/family relationships.

\section{Key words}

Aged care, Family participation, Person-centred care, Residential care, Staff/Family relationships

\section{I ntroduction}

A good relationship between staff and families in residential aged care facilities (RACF's) is essential to the provision of high quality care. Family and friends of residents are an extension of the person and their establishment of personhood which has long been recognised in the literature ${ }^{[1]}$ and the subject of debate in philosophy and law. Personal identity is constituted in, and sustained through, our relationships with others ${ }^{[2]}$. RACF's settings have grappled with the idea of personhood in resident care, possibly due to the predominant historical, task focused models of care employed. In recent years there has been a shift in government policy in the aged care setting in Australia to embrace person-centred care and 'humanise' work practices ${ }^{[3]}$. 
An essential aspect of person-centred care is an in depth knowledge of the person being cared for ${ }^{[4]}$ and the consideration of the residents broader relationships with family and friends. Previous research reports that residential aged care settings are not conducive to constructive staff/family relationships ${ }^{[5,6]}$. When considering the fundamental involvement of families that is necessary to achieve person-centred care in the RAC setting, the element of relationships requires further exploration to better understand barriers which may exist.

This research project aimed to identify staff opinions of working with families in RAC settings to identify any potential barriers in these rural settings, which may hinder person-centred practices. None of the previous studies accessed were explicitly described as rural, and the authors hypothesised that the relationships in rural settings would not reflect the results found in the literature. It was assumed that the social proximity of staff and families in these small Australian townships would translate into more favourable staff perceptions than those described in the literature.

\section{Methodology}

\subsection{Setting}

The consenting facilities were three publicly funded 30 bed high care facilities. The three facilities were chosen due to their similarity and an existing relationship with researchers from the University of Melbourne's Rural Health Academic Network, which provides research and education within the prescribed region. The towns in which the facilities were located varied in population from as little as 5,000 - 14,000 people, but all relied on agriculture as the main industry ${ }^{[7]}$.

\subsection{Recruitment}

This was a small exploratory, cross-sectional convenience sample of residential aged care staff who were recruited for the quantative study. All staff of the facilities was invited to voluntarily participate by poster displays and emails informing them about the process and aim of the quantative study. Short questionnaires, developed by the researchers, were distributed to all staff by their own managers by attaching them to payslips or placing them in staff mail boxes. Consent was implied by anonymous return of the completed questionnaire. The questionnaires were distributed at each facility on the same day, with a four week return date for inclusion in the study.

\subsection{Measurement tool}

The questionnaire used sought demographic information about the participant's age, years of experience, level of training and the predominant shifts worked. Furthermore, staff opinions about working with families were explored by modification of a previously validated tool used in the mental health field in Australia ${ }^{[8]}$. The scale sought responses to 20 statements about families and working with families on a 5-point scale from 'strongly disagree' to 'strongly agree'. The scale was initially designed to study the opinions of mental health workers. In this study, where the words "Mental Health Workers" appeared they were replaced with "Aged Care Workers". The questionnaire was also reduced from 40 statements to 20 statements for brevity and relevance to the aged care setting. The statements included in the questionnaire can be seen in the results section. An open ended question was also included at the end of the questionnaire inviting comments from staff about working with families.

Although the tool has not been validated in this setting, to our knowledge no other suitable tool existed to determine the required information. This tool was chosen because it explored attitudes and perceptions of staff working with families within an Australian health service setting.

The questionnaire was pretested with a similar participant group, in another setting, to ensure clarity and participant understanding. Consistent responses during the pretesting phase and obtained from the study participants indicated reliability of the tool. This was a small exploratory study conducted at a local level to inform local practice. Psychometric 
testing of the tool is not appropriate in this case, as a resulting score that implies an outcome, was not the aim of this study. Further studies would require psychometric testing of the modified tool. The results were not intended to be generalized beyond the study population. A copy of the questionnaire can be obtained from the corresponding author.

\subsection{Statistics}

Data from the survey was analysed using SPSS version 17 software. Given the small sample size univariate statistics are reported.

\subsection{Ethics}

The research project was approved by the University of Melbourne Human Research and Ethics Committee (Project No 1033333.1).

\section{Results}

\subsection{Participants}

Staff who responded to the survey included registered nurses, enrolled nurses and one personal care attendant. In Australia basic undergraduate training for registered nurses is a three year baccalaureate degree, for enrolled nurses a one year diploma and for personal care attendants a 26 week certificate course. Publicly funded aged care facilities offer eight hour shifts, morning afternoon and night.

Table 1. Participant characteristics $(n=46)$

\begin{tabular}{llll}
\hline & Range & Mean & Standard Deviation \\
\hline Age & $22-61$ & 46 & 9.8 \\
Years of experience & $1-40$ & 19 & 12.7 \\
& & $n$ & $(\%)$ \\
Level of training or qualification & Registered Nurse & 8 & 18 \\
& Enrolled Nurse & 36 & 80.4 \\
& Personal Care attendant & 1 & 2.2 \\
Shifts predominantly worked (8 hours) & Morning & $n$ & $(\%)$ \\
& Afternoon & 15 & 33 \\
& Night & 7 & 15 \\
& Mixture & 5 & 11 \\
\hline
\end{tabular}

The eligible sample size was 98 care staff, of whom 46 (46.9\%) returned completed questionnaires.

As shown in Table 1, the sample consisted of staff with a mean age of 46 years, who had an average of 19 years of experience. The majority (80.4\%) worked as enrolled nurses, and predominantly (41\%) worked a mixture of shifts. Despite their proximity, none of the staff reported working in more than one facility. There was no correlation between the designation of staff and their responses to the statements in the survey, nor did responses differ greatly between facilities and thus results were pooled for presentation.

\subsection{Survey results}

The statements about working with families presented in the survey were a combination of positive and negative statements. The fourteen negative statements and staff responses to the statements are shown in Table 2 . There were only 
three negative statements that the majority of staff disagreed with, most responses indicating staff have a negative perception of working with families. There were only a small number of neutral responses to the statements.

Table 2. Negative statements about working with families and staff responses $(\mathrm{n}=46)$

\begin{tabular}{|c|c|c|c|c|c|c|}
\hline & \multicolumn{2}{|c|}{ Disagree } & \multicolumn{2}{|c|}{ Don't know } & \multicolumn{2}{|c|}{ Agree } \\
\hline & $\mathbf{n}$ & $\%$ & n & $\%$ & $\mathbf{n}$ & $\%$ \\
\hline $\begin{array}{l}\text { Families who do NOT initiate } \\
\text { contact with staff often want it } \\
\text { anyway }\end{array}$ & 3 & 6.5 & 7 & 15 & 36 & 78 \\
\hline $\begin{array}{l}\text { Families want more information } \\
\text { than they are currently getting }\end{array}$ & 8 & 17 & 7 & 15 & 31 & 67 \\
\hline $\begin{array}{l}\text { Many families are angry and } \\
\text { frustrated with aged care workers }\end{array}$ & 9 & 20 & 2 & 4.3 & 35 & 76 \\
\hline $\begin{array}{l}\text { Families often undermine treatment } \\
\text { efforts }\end{array}$ & 6 & 13 & 5 & 11 & 35 & 76 \\
\hline $\begin{array}{l}\text { Families are often resistant to staff } \\
\text { suggestions }\end{array}$ & 14 & 30 & 2 & 4.3 & 30 & 65 \\
\hline $\begin{array}{l}\text { Working with families is often a } \\
\text { battle }\end{array}$ & 10 & 22 & 0 & & 36 & 78 \\
\hline $\begin{array}{l}\text { Aged care workers are experts who } \\
\text { should know more than families } \\
\text { about managing residents }\end{array}$ & 30 & 67 & 4 & 8.9 & 11 & 24 \\
\hline $\begin{array}{l}\text { Routine consultations with families } \\
\text { are unnecessary }\end{array}$ & 38 & 83 & 0 & & 8 & 17 \\
\hline $\begin{array}{l}\text { The responsibility of aged care } \\
\text { workers lies primarily with the } \\
\text { residents and not families }\end{array}$ & 33 & 72 & 1 & 2.2 & 12 & 26 \\
\hline $\begin{array}{l}\text { If one includes significant friends, } \\
\text { the definition of family becomes } \\
\text { more confused for the aged care } \\
\text { worker }\end{array}$ & 17 & 37 & 6 & 13 & 23 & 50 \\
\hline $\begin{array}{l}\text { Working with families is difficult } \\
\text { because the aged care worker is } \\
\text { faced with competing opinions } \\
\text { about what resident information } \\
\text { should be disclosed }\end{array}$ & 14 & 31 & 2 & 4.4 & 29 & 64 \\
\hline $\begin{array}{l}\text { The interests of the resident are } \\
\text { often at odds with those of his/her } \\
\text { family }\end{array}$ & 6 & 13 & 1 & 2.2 & 39 & 85 \\
\hline $\begin{array}{l}\text { Working with families from a Non } \\
\text { English speaking background is } \\
\text { often confusing }\end{array}$ & 8 & 18 & 5 & 11 & 32 & 71 \\
\hline $\begin{array}{l}\text { Working with families non } \\
\text { judgmentally is made more difficult } \\
\text { because aged care workers work on } \\
\text { such a close personal level with } \\
\text { residents }\end{array}$ & 15 & 33 & 2 & 4.3 & 29 & 63 \\
\hline
\end{tabular}

Table 3 illustrates the six positive statements presented to staff and their responses to them. Three of the statements staff agreed with except $83 \%$ of respondents felt that staff were blamed when things go badly for the resident, and $87 \%$ believe 
that family members are hostile without good reason. There was one statement about the ease of deciding which family members to work with which staff opinions were evenly divided on.

Table 3. Positive statements about families and staff responses $(n=46)$

\begin{tabular}{|c|c|c|c|c|c|c|}
\hline & \multicolumn{2}{|c|}{ Disagree } & \multicolumn{2}{|c|}{ Don't know } & \multicolumn{2}{|c|}{ Agree } \\
\hline & $\mathbf{n}$ & $\%$ & $\mathbf{n}$ & $\%$ & n & $\%$ \\
\hline $\begin{array}{l}\text { Family members are never } \\
\text { hostile to staff without good } \\
\text { reason }\end{array}$ & 40 & 87 & 1 & 2.2 & 5 & 11 \\
\hline $\begin{array}{l}\text { The relatives of a resident } \\
\text { should be encouraged to } \\
\text { participate in the care and } \\
\text { treatment of their relative }\end{array}$ & 6 & 13 & 1 & 2.2 & 39 & 85 \\
\hline $\begin{array}{l}\text { Families rarely blame staff } \\
\text { when things are going badly } \\
\text { with the resident }\end{array}$ & 38 & 83 & 2 & 4.3 & 6 & 13 \\
\hline $\begin{array}{l}\text { With proper training families } \\
\text { are able to effectively manage } \\
\text { the problem behaviours of } \\
\text { their relative }\end{array}$ & 13 & 28 & 11 & 24 & 22 & 48 \\
\hline $\begin{array}{l}\text { Aged care workers should } \\
\text { encourage involvement of } \\
\text { families with self-help groups } \\
\text { or family organisations }\end{array}$ & 2 & 4.3 & 2 & 4.3 & 42 & 91 \\
\hline $\begin{array}{l}\text { It is easy to decide which } \\
\text { family members to work with } \\
\text { in relation to resident care }\end{array}$ & 19 & 41 & 8 & 17 & 19 & 41 \\
\hline
\end{tabular}

The overall negative perceptions expressed by staff to the statements in Table 2 and Table 3 are also supported by some qualitative responses reported by staff in the open ended section, with one respondent saying:

“Some families can be very stressful to deal with. It doesn't matter what staff do, it won't be right.......... $\quad$ and

"Some family members are difficult to deal with. There needs to be mutual respect between staff and residents families as well as trust”.

Respondents to the open ended questions also commented on hostility and anger towards staff by residents and their families, with comments such as:

"Abuse (mainly verbal) from families is increasing, this is difficult for staff to cope with, there is minimal support for staff when this occurs" and,

"...you can receive a lot of abuse from some families; you just have to keep your cool...."

Another respondent reported:

"Families only want what is best for the resident but may not always express this without hostility or criticism".

Although the survey responses indicated that staff perceived families to be able to manage the problem behaviours of their relative some respondents to the open ended question did not always agree that families are experts at managing their relatives, with one respondent commenting: 
"Families sometimes lack insight into the level of care that is needed to maintain resident's needs."

Staff positively reported that families should be encouraged to participate in the care of their relative. As can be seen in Table 3, eighty five percent report that families should be encouraged to participate in care, and the majority also responding that there should be routine consultations with families (83\%) and aged care workers have a responsibility to families and not primarily to the resident (72\%).

Qualitative responses overall support this opinion, with one respondent reporting:

"Families need to feel welcomed and encouraged to share info and care of residents with aged care staff".

One staff member expressed at it was difficult to ascertain the level of involvement families wished to have, and possible reasons for this:

"It is difficult to tell the level of involvement families are willing to have with their relative. I feel mainly due to lack of innovation to do so; lack of education and lack of initiative from the family and management."

There were 32 (69.5\%) responses reported by staff when invited to comment on working with residents families. Responses generally supported the opinions expressed in the questionnaire. There were six comments, however, that related to lack of support from management for staff when families were perceived as problematic. The examples were not isolated to one facility but common to all and included:

"Not enough support from management for staff who care for difficult residents and family members"

"I don't think staff get enough support from management when dealing with difficult families"

"There is minimal support for staff when abuse occurs"

\section{Discussion}

The response rate to this study was low (47\%); however this is not dissimilar to other Australian studies surveying nurses ${ }^{[9-12]}$. Recruitment of participants is important for controlling bias and obtaining a representative sample, however rural research is notorious for small sample sizes and resultant difficulty in showing statistical significance ${ }^{[13]}$. The authors of this study opine that the low response rate whilst consistent with others could be biased by those with a negative attitude to families completing the survey ${ }^{[14]}$.

Despite this study's low response rate, the results are consistently the same, that nursing staff in aged care facilities view families negatively.

To ameliorate non response bias, two non-respondents from each site ( $10 \%$ of non-respondents overall) were surveyed as a control method. This is a common method of controlling bias in questionnaires when response rates are low, to determine if those who did not respond differed greatly in their opinion from those who did ${ }^{[15,16]}$. The six non respondents who participated in this exercise demonstrated that their opinions did not vary from those who did respond to the survey in the first instance with $83 \%(\mathrm{n}=5)$ agreeing that families who do not initiate contact with staff want it anyway, and that many families are angry and frustrated with aged care workers. The same percentage agreed that the interests of residents are at odds with those of his/her family, $66 \%(\mathrm{n}=4)$ disagreed that family members are never hostile without good reason and $50 \%(n=3)$ agreed that working with families is a battle. Although this does not allow generalization of how the entire sample might have responded it does lend some validity that non respondents to the questionnaire share similar opinions on working with families to those who did respond. 
The authors assumed that the perceptions of staff in rural locations would not reflect the negative findings in the literature, due to the social proximity of staff and families in these settings. The fact that the findings do not differ from metropolitan settings, or studies undertaken worldwide, suggests that it may be the structure of the facilities and/or work processes which facilitate the negative attitudes of staff.

The study aimed to explore staff opinions about working with families in rural residential aged care, as a possible barrier to person-centred care. The results demonstrate that high proportions of aged care staff do perceive families as problematic to work with, and that staff frequently encounter angry and hostile exchanges with residents' families. Despite this staff reported that relatives were knowledgeable about their relatives and should be encouraged to participate in their care.

Staff demonstrate an awareness that relatives possess knowledge about residents and in theory welcome their participation, which could potentially be used to improve care (i.e. through life story telling for residents with dementia), but that this may be precluded by an underlying hostile relationship between staff and families. Furthermore a number of staff provided qualitative accounts of an expressed a perceived lack of support from management when they encounter problematic, hostile and angry families.

Aged care staff's theoretical support of family participation has already been identified ${ }^{[5,6,17]}$ by other studies and supported by this study. Despite the earlier findings of research, the recency of this study suggests little has changed in staff/family relationships in the aged care setting.

Staff in this study recognise the value of families intimate knowledge of the resident's and their potential to improve care. Families remaining involved and participating in care has been shown to be beneficial to residents with and without cognitive impairment, in previous studies ${ }^{[18-20]}$. Even very early studies ${ }^{[21]}$ suggest that maximum family involvement is a powerful treatment resource.

Like other studies ${ }^{[6]}$ this study reports that aged care staff perceive families as being difficult to work with. There is evidence that developing care partnerships with families reaps benefits for residents and staff alike ${ }^{[20]}$, suggesting a necessity for staff and families to find solutions to the existing barriers of working collaboratively. In addition, another study found that where families had good relationships with staff, care for residents was perceived as higher quality ${ }^{[22]}$. One study reports that a good knowledge of the resident minimizes the likelihood of difficulty in working with them and their families ${ }^{[23]}$. The underlying reasons for staff perceptions in this study were not explored by the tool utilized.

Of greatest concern was the finding in this study that rural aged care staff frequently encounter hostile situations with families, and that families were perceived as being angry and frustrated with them. Maas ${ }^{[24]}$ study reports that anger and hostily was increased when relatives felt excluded from care in institutionalized settings. Alternatively another study concluded that increased family participation may result in decreased satisfaction because they see firsthand problems with nursing home care and because a meaningful caregiving role after institutionalization is not facilitated by nursing homes ${ }^{[25]}$. Hostility and aggression towards nurses is well recognized in the literature ${ }^{[26]}$ and like this study it is suggested that managers offer little support for staff affected. It is also implicated as a major factor in declining retention rates. Recent research suggests that staff in aged care facilities could be assisted in their roles if debriefing and pastoral care was available, and recognition given to stressful relationships with families ${ }^{[5]}$.

If staff in aged care settings hope to provide optimal care to residents through a model of person-centred care, then it is crucial that they develop good relationships with families. The cognitive deficits associated with dementia in aged care settings often exclude residents as true partners in care, and staff are wholly reliant on families to provide essential information. Good relationships and collaboration with families may also increase staff retention, increase families perception of the quality of care provided, reduce hostility towards care staff and improve overall resident outcomes. 
The authors assumed that staff/family relationships in rural RACF's would be perceived favourably by staff. As no other published studies have a rural focus, this study adds an important dimension to the current literature. The negative perceptions expressed suggest that it would be useful for all RACF's to employ a measurement tool to monitor their performance in relating to families, and establish more effective ways of forming partnerships in care. This study also supports the emerging literature that aged care staff require skills, not only in care, but also staff- family- resident dynamics, conflict resolution and customer service ${ }^{[5]}$.

\section{Limitations}

This study has limitations which must be considered when interpreting the findings. The validity of the measurement tool has not been tested in this setting and a larger study of this kind would demand psychometric testing of the tool to allow external validity and generalisability of the results.

The convenience sampling strategy limits the ability to make generalisations to wider aged care settings. The small sample size means that the views expressed here cannot be assumed to be shared by all aged care staff, even within the facilities surveyed.

The theoretical support of other findings does imply usefulness as a pilot study for a larger research project and may provide a useful framework for change in similar Australian settings. As with all research studies, the reader will be the final arbiter of the research's broader transferability and relevance.

\section{Conclusion}

The significant opinion among rural aged care staff that working with families in residential aged care is problematic has clear implications. Providing person-centred care for residents is more than an ideal expressed in government policy as a preferred model of care. The cognitive deficits commonly associated with residents demands the participation of their families to achieve this. The current climate of staff/family relationships in the aged care setting requires thorough research to definitively identify causes of dissatisfaction and hostility, and explore factors which may enable both parties to overcome these barriers.

The issues raised in this study, and identified by other studies, requires attention. Aged care setiings cannot hope to provide a gold standard of care for residents until person-centred care, in collaboration with families can be achieved. Determining staff perceptions of working with families, by utilising a similar tool will at least help RACF's begin to monitor their performance in staff/family relationships.

\section{Acknowledgements}

This project was funded by the Victorian Department of Health as part of the Evaluating Effective Participation projects.

\section{References}

[1] Brooker, D. What is person-centred care in dementia? Reviews in Clinical Gerontology. 2004; 13(3): $215-222$. http://dx.doi.org/10.1017/S095925980400108X

[2] Kompridis, N. Technology's Challenge to Democracy: What of the Human? Parrhesia. 2009; 8.

[3] Department of Health, 2012. Maintaining personal identity: respect and dignity [Internet]. Dementia-friendly environments. A guide for residential care. Available from: http://www.health.vic.gov.au/dementia/changes/personal-identity.

[4] Kitwood, T., 1997. Dementia reconsidered:The person comes first. Buckingham: Open University Press.

[5] Bauer, M., and Nay, R. Improving family-staff relationships in assisted living facilities: the views of family. Journal of Advanced Nursing. 2011; 67(6): 1232-1241. PMid:21306421 http://dx.doi.org/10.1111/j.1365-2648.2010.05575.x 
[6] Haesler, E., Bauer, M. \& Nay, R., 2006. Constructive staff-family relationships in the care of older adults in the institutional setting. A systematic review. Australian Centre for Evidence Based Aged Care (ACEBAC). PMCid:1622802

[7] Ervin, K., Finlayson, S., Cross, M. The management of behavioural problems associated with dementia in rural aged care. Collegian. 2012; 19: 85-95. PMid:22774350 http://dx.doi.org/10.1016/j.colegn.2012.02.003

[8] Farhall, J., Webster, B., Hocking, B., Leggatt, M, Reiss, C. \& Young, J. Training to enhance partnerships between mental health professionals and family caregivers: A comparative study. . Psychiatric Services. 1998; 49(11): 1488-1490. PMid:9826255

[9] Mills J, Field J, and Cant R. The Place of Knowledge and Evidence in the Context of Australian General Practice Nursing. Worldviews on Evidence Based Nursing. 2009; 6(4): 219-228. PMid:19712050 http://dx.doi.org/10.1111/j.1741-6787.2009.00163.x

[10] Gething L, et al. Fostering Nursing Research among Nurse Clinicians in an Australian Area Health Service. The Journal of Continuing Education in Nursing. 2001; 32(5): 228 - 239. PMid:11868740

[11] Bonner A and Sando J. Examining the knowledge, attitude and use of research by nurses. Journal of Nursing Management. 2008; 16: 334-343. PMid:18324993 http://dx.doi.org/10.1111/j.1365-2834.2007.00808.x

[12] Retsas A and Nolan M. Barriers to nurses' use of research: an Austrlaian hospital study. International Journal of Nursing Studies. 1999; 36: 335-343. http://dx.doi.org/10.1016/S0020-7489(99)00027-9

[13] McGrail, M., Jones, R., Robinson, A., Rickard, C., Burley, M., Drysdale, M. The planning of rural health research: Rurality and rural population issues. Rural and Remote Health. 2005; 5(426).

[14] Hutchinson AM and Johnston L. Bridging the divide: a survey of nurses' opinions regarding barriers to, and facilitators of, research utilization in the practice setting. Journal of Clinical Nursing. 2004; 13: 304-315. PMid:15009333 http://dx.doi.org/10.1046/j.1365-2702.2003.00865.x

[15] Clausen, J., \& Ford, R. Estimating Nonresponse Bias in Mail Surveys. Journal of the American Statistical Association. 2011; 42(1947).

[16] Armstrong, J., and Overton, T. Estimating Nonresponse Bias in Mail Surveys. Journal of Marketing Research. 1977 ; $14: 396-402$. http://dx.doi.org/10.2307/3150783

[17] Toye, C., Percival, P. \& Blackmore, A. Satisfaction with nursing home care of a relative: does inviting greater input make a difference? Collegian. 1996; 2(April).

[18] Gaugler, J., Anderson, K., Pearlin, L. Family involvement in nursing homes: effects on stress and wellbeing. Ageing and mental health. 2004; 8(1): 65-75. PMid:14690870 http://dx.doi.org/10.1080/13607860310001613356

[19] Fossey, J., Ballard, C., Juszczak, E., James, I., Alder, N., Jacoby, R. \& Howard, R. Effect of enhanced psychosocial care on antipsychotic use in nursing home residents with severe dementia: cluster randomised trial. British Medical Journal. 2006; 332(March): 756-761. PMid:16543297 http://dx.doi.org/10.1136/bmj.38782.575868.7C

[20] Marquis, R., Heather Freegard, H., Hoogland, L. Influences on positive family involvement in aged care: An ethnographic view. . Contemporary Nurse. 2004; 16(3): 178-186. PMid:15125100 http://dx.doi.org/10.5172/conu.16.3.178

[21] York, J., Calsyn, R. Family involvement in nursing homes. The Gerontologist. 1977; 17(6): 500-505. PMid:924171 http://dx.doi.org/10.1093/geront/17.6.500

[22] Bowers, B. Family Perceptions of Care in a Nursing Home. The Gerontologist. 1998; 28(3): 361-368. http://dx.doi.org/10.1093/geront/28.3.361

[23] Macdonald, M. Origins of Difficulty in the Nurse-Patient Encounter. Nursing Ethics. 2007; 14(4): 510-521. PMid:17562730 http://dx.doi.org/10.1177/0969733007077885

[24] Maas, M., Reed, D., Park, M., Specht, J. et al. Outcomes of family involvement in care intervention for caregivers of individuals with dementia. Nursing research. 2004; 53(2). PMid:15084992 http://dx.doi.org/10.1097/00006199-200403000-00003

[25] Levy-Storms, L., Miller- Martinez, D. Family Caregiver Involvement and Satisfaction with Institutional Care during the 1st Year after Admission. Journal of Applied Gerontology. 2005; 24(2): 160-174. http://dx.doi.org/10.1177/0733464804272102

[26] Jackson, D., Clare, J., Mannix, J. Who would want to be a nurse? Violence in the workplace - a factor in recruitment and retention. Journal of Nursing Management. 2002; 10(1): 13-20. PMid:11906596 http://dx.doi.org/10.1046/j.0966-0429.2001.00262.x 